\title{
Ethnic difference in the prevalence of systemic lupus erythematosus
}

\author{
H. H. HART, R. R. GRIGOR, AND D. E. CAUGHEY \\ From the Department of Rheumatology, Auckland Public Hospital, Park Road, Auckland 1, New Zealand
}

SUMmARY A retrospective study of systemic lupus erythematosus (SLE) was carried out in Auckland, New Zealand, for the years 1975 to 1980 inclusive. One hundred and fifty-one patients were found of which 106 fulfilled the American Rheumatism Association criteria. There were 15 deaths. Age-adjusted prevalence rates per 100000 were estimated for all cases at the end of 1980 as follows: white $14 \cdot 6$, Polynesian $50 \cdot 63$, and other $19 \cdot 11$. There was a preponderance of females in each ethnic group, average $87 \%$ of all cases. Age-adjusted mortality rates per million patient years were: whites $2 \cdot 5$ and Polynesians $13 \cdot 0$. Survival curves for both ethnic groups were similar. The prevalence rate in New Zealand Polynesians is significantly higher than in white counterparts which confirms the observation that the disease is commoner in the pigmented races.

Epidemiological studies have shown or suggested ethnic differences in SLE prevalence rates. Studies in New York City, ${ }^{1}$ San Francisco, ${ }^{2}$ and Jefferson County, Alabama, ${ }^{3}$ have shown a 2.4 to 3.3 times higher prevalence of the disease in blacks than in whites. Hospital based studies in West Malaysia ${ }^{4}$ and Singapore ${ }^{5}$ have suggested a greater prevalence in orientals. A similar high prevalence rate has been claimed for blacks in Jamaica, ${ }^{6}$ and a recent study from Hawaii ${ }^{7}$ has shown rates for orientals and Polynesians 3 to 4 times that for whites.

Ethnic differences in mortality rates from systemic lupus erythematosus have also been found. In the United States ${ }^{8}$ from 1968 to 1972 the rates for white and black females were $5 \cdot 2$ and 14.8 per million person years respectively. The overall rate for blacks was 2.6 times that for whites. Similar rates have been demonstrated for the period 1972 to $1976 .^{9}$

This study describes the results of a retrospective survey of the ethnic differences of SLE in Auckland, New Zealand. Auckland is an appropriate location to conduct such a study, because there is a large population of both whites and Polynesians available for comparison. The National Census statistical area corresponds to that serviced by the 3 main hospitals. The same area is serviced by a central histopathology and immunology laboratory, and there is close liaison between these hospitals and physicians not based on hospitals.

\footnotetext{
Accepted for publication 21 July 1982.
}

Correspondence to Dr H. H. Hart.

\section{Patients and methods}

Medical records with a discharge diagnosis of SLE were retrieved from the 3 general hospitals for the period 1 January 1975 to 1 January 1981. The records of patients with significant antinuclear antibody results and renal biopsies consistent with SLE were also traced. A questionnaire was circulated among all physicians not based on hospitals in order to collect all those patients who had not been admitted to hospital. Government death records with SLE listed as the primary cause of death were also reviewed. The final list was checked against the national death register to exclude unrecorded deaths. Patients referred for hospital treatment from outside the area were excluded (Table 1).

Ethnic group was self-declared in both the National Census and hospital record data. The Polynesian ethnic group is made up of Maori, Pacific Islander, and people of mixed blood.

The criteria suggested by Fries and Holman ${ }^{10}$ were used to identify patients. These criteria require a multisystem disease with specific manifestations involving more than one system, the presence of appropriate autoantibodies, and the specific exclusion of other diseases with similar features.

The American Rheumatism Association (ARA) preliminary criteria ${ }^{11}$ were also applied to all patients. Patients with 4 or more criteria were classified as definite SLE and those with 3 or fewer as possible SLE. The data used for subsequent calculations in this study were based on those patients identified by the Fries and Holman criteria. ${ }^{10}$ 
Table 1 Population estimates for Auckland by age, sex, and ethnic group (1976 National Census)

\begin{tabular}{llrrrr}
\hline Age & Sex & White & Polynesian & Other & \multicolumn{1}{l}{ Total } \\
\hline $0-14$ & M & 88745 & 23679 & 5275 & 117699 \\
& F & 84080 & 22456 & 5094 & 111630 \\
$15-24$ & M & 56537 & 11146 & 3233 & 70916 \\
& F & 55797 & 11853 & 2825 & 70475 \\
$25-34$ & M & 49073 & 7600 & 2627 & 59300 \\
& F & 50632 & 8294 & 2355 & 61281 \\
$35-44$ & M & 37304 & 4991 & 1667 & 43962 \\
& F & 36316 & 5098 & 1564 & 42978 \\
$45-64$ & M & 66084 & 4059 & 2721 & 72864 \\
& F & 67246 & 4161 & 3264 & 74671 \\
$65+$ & M & 27275 & 682 & 1735 & 29692 \\
& F & 38132 & 859 & 2908 & 41899 \\
Total & M & 325017 & 52157 & 17258 & 394433 \\
& F & 332203 & 52721 & 18010 & 402934 \\
\hline
\end{tabular}

The prevalence of SLE was estimated by counting all patients found and subtracting deaths occurring during the period. These figures were related to the population estimates derived from the 1976 National Census. Age-specific mortality rates for SLE were calculated from the white population as standard. The significance of the difference between groups was determined. ${ }^{12}$ Survival curves were constructed for both ethnic groups. ${ }^{13}$

\section{Results}

One hundred and fifty-one patients with SLE were identified by the criteria of Fries and Holman. ${ }^{10}$ There were 15 deaths, leaving 136, including 96 patients with 4 or more ARA criteria. Females predominated, making up 123 of the remaining 136 patients. Although whites constitute $83 \%$ of the Auckland population, only $71 \%$ of the definite cases of SLE were from this group. The incidence of lupus manifestations for Polynesians, whites, and all Auckland cases was compared with those in a series of mixed race compiled by rheumatologists ${ }^{11}$ (Table 2). Symptoms which may not be volunteered by the patient and which may require specific questions to discover, such as photosensitivity, alopecia, and pleuritis, were less frequently recorded, but this is to be expected in a retrospective study. Similarly manifestations requiring special skills for their detection, such as discoid lupus, arthritis, and urinary casts, were also less frequent than in the reference series. Notable ethnic differences were the lower incidence of Raynaud's phenomenon, photosensitivity, and arthritis in the Polynesian group and a higher incidence of chronically false positive VDRL (Venereal Disease Reference Laboratories test), haemolytic anaemia and thrombocytopenia. Psychosis was lower
Table 2 Percentage frequency of ARA criteria in whites, Polynesians, and the patient group used to construct the ARA criteria*

\begin{tabular}{|c|c|c|c|c|}
\hline Criteria & $\begin{array}{l}\text { ARA } \\
\text { group } \\
(245)\end{array}$ & $\begin{array}{l}\text { Polynesian } \\
\text { group } \\
\text { (34) }\end{array}$ & $\begin{array}{l}\text { White } \\
\text { group } \\
\text { (96) }\end{array}$ & $\begin{array}{l}\text { All } \\
\text { patients } \\
\text { (136) }\end{array}$ \\
\hline Facial erythema & $63 \cdot 7$ & 50 & $58 \cdot 3$ & $58 \cdot 3$ \\
\hline Discoid & $17 \cdot 1$ & $5 \cdot 8$ & $2 \cdot 1$ & 2.9 \\
\hline Raynaud's disease & $20 \cdot 0$ & $14 \cdot 7$ & 36.5 & $30 \cdot 1$ \\
\hline Alopecia & $43 \cdot 3$ & $26 \cdot 5$ & 21.9 & $23 \cdot 5$ \\
\hline Photosensitivity & $36 \cdot 7$ & $20 \cdot 6$ & $31 \cdot 3$ & $27 \cdot 9$ \\
\hline Oral ulceration & $15 \cdot 1$ & $23 \cdot 5$ & $12 \cdot 5$ & $15 \cdot 4$ \\
\hline Arthritis & 88.9 & $58 \cdot 8$ & 69.8 & $68 \cdot 3$ \\
\hline LE cells & 91.8 & $44 \cdot 1$ & $41 \cdot 7$ & 44.9 \\
\hline \multicolumn{5}{|l|}{ False positive } \\
\hline VDRL & $11 \cdot 8$ & $23 \cdot 5$ & $11 \cdot 5$ & $14 \cdot 0$ \\
\hline Proteinuria & $19 \cdot 6$ & $26 \cdot 5$ & $16 \cdot 7$ & $19 \cdot 9$ \\
\hline Casts & $47 \cdot 8$ & $29 \cdot 4$ & $11 \cdot 5$ & $17 \cdot 6$ \\
\hline Pleuritis & $60 \cdot 4$ & $41 \cdot 2$ & $40 \cdot 6$ & 41.9 \\
\hline Pericarditis & $18 \cdot 8$ & $17 \cdot 6$ & $10 \cdot 4$ & $15 \cdot 4$ \\
\hline Psychosis & $19 \cdot 2$ & $2 \cdot 9$ & $5 \cdot 2$ & $7 \cdot 4$ \\
\hline Convulsions & $12 \cdot 7$ & $8 \cdot 8$ & $2 \cdot 8$ & $4 \cdot 4$ \\
\hline \multicolumn{5}{|l|}{ Haemolytic } \\
\hline anaemia & $16 \cdot 3$ & $17 \cdot 6$ & $3 \cdot 1$ & $6 \cdot 6$ \\
\hline Leucopenia & $39 \cdot 6$ & $47 \cdot 1$ & $35 \cdot 4$ & $36 \cdot 0$ \\
\hline Platelets & $11 \cdot 4$ & $35 \cdot 3$ & $11 \cdot 5$ & $16 \cdot 2$ \\
\hline
\end{tabular}

"Number if cases shown in parentheses.

in all groups, probably because the retrospective differentiation of cerebral lupus from steroid psychosis and reactive depression was extremely difficult. None of these differences was statistically significant (Table 3).

The prevalence rates estimated for the end of 1980 are shown in Table 4. The overall rate for Auckland was 18 per 100000 , with rates for women aged 15 to

Table 3 Patients with the diagnosis of SLE resident in Auckland on 1 January $1981^{*}$

\begin{tabular}{|c|c|c|c|c|c|c|c|c|}
\hline \multirow[t]{2}{*}{ Age } & \multicolumn{2}{|c|}{ White } & \multicolumn{2}{|c|}{ Polynesian } & \multicolumn{2}{|c|}{ Other } & \multicolumn{2}{|l|}{ Total } \\
\hline & $\boldsymbol{M}$ & $F$ & $\boldsymbol{M}$ & $\boldsymbol{F}$ & $\boldsymbol{M}$ & $F$ & $\boldsymbol{M}$ & $F$ \\
\hline \multirow[t]{2}{*}{$0-14$} & (0) & (0) & (0) & (0) & (0) & (0) & (0) & (0) \\
\hline & 0 & 0 & 0 & $\begin{array}{c}0 \\
(11)\end{array}$ & $\begin{array}{c}0 \\
(0)\end{array}$ & $\begin{array}{l}0 \\
(0)\end{array}$ & $\begin{array}{c}0 \\
(2)\end{array}$ & $\begin{array}{c}0 \\
18)\end{array}$ \\
\hline $15-24$ & 0 & 0 & 1 & 1 & (U) & 3 & 1 & 4 \\
\hline \multirow[t]{2}{*}{$25-34$} & (3) & (32) & (1) & (9) & (1) & (3) & (5) & (44) \\
\hline & 0 & 11 & 0 & 3 & 0 & 0 & 0 & 14 \\
\hline \multirow[t]{2}{*}{$35-44$} & (3) & (12) & (1) & (3) & (0) & (2) & (4) & (17) \\
\hline & $\begin{array}{c}2 \\
(2)\end{array}$ & $\begin{array}{c}2 \\
(28)\end{array}$ & $\begin{array}{c}0 \\
(0)\end{array}$ & $\begin{array}{l}1 \\
(6)\end{array}$ & $\begin{array}{c}0 \\
(0)\end{array}$ & $\begin{array}{c}0 \\
(0)\end{array}$ & $\begin{array}{c}2 \\
(2)\end{array}$ & $\begin{array}{c}3 \\
(34)\end{array}$ \\
\hline $45-64$ & 2 & 9 & 0 & 2 & 0 & 0 & 2 & 11 \\
\hline \multirow[t]{2}{*}{$65+$} & (0) & (8) & (0) & (2) & (0) & (0) & (0) & (10) \\
\hline & 0 & 3 & 0 & 0 & 0 & 0 & 0 & 3 \\
\hline \multirow[t]{2}{*}{ Total } & (9) & (87) & (3) & (31) & (1) & (5) & (13) & (123) \\
\hline & 4 & 25 & 1 & 7 & 0 & 3 & 5 & 35 \\
\hline
\end{tabular}

-The figure in parentheses represents the total number of patients and the figure below the number fulfilling fewer than 4 ARA criteria. 
Table 4 Estimated prevalence of SLE in Auckland at the end of 1980

\begin{tabular}{|c|c|c|c|c|c|c|c|c|}
\hline \multirow[t]{2}{*}{ Age } & \multicolumn{2}{|c|}{ White } & \multicolumn{2}{|c|}{ Polynesian } & \multicolumn{2}{|c|}{ Other } & \multicolumn{2}{|c|}{ Total } \\
\hline & No. & Rate & No. & Rate & No. & Rate & No. & Rate \\
\hline $0-14$ & 0 & 0 & 0 & 0 & 0 & 0 & 0 & 0 \\
\hline $15-24$ & 8 & $7 \cdot 12$ & 12 & $52 \cdot 2$ & 0 & 0 & 20 & $14 \cdot 14$ \\
\hline $25-34$ & 35 & $35 \cdot 1$ & 10 & 62.9 & 4 & $80 \cdot 28$ & 49 & 40.63 \\
\hline $35-44$ & 15 & $20 \cdot 4$ & 4 & 39.64 & 2 & 61.9 & 21 & $24 \cdot 15$ \\
\hline $45-64$ & 30 & 22.5 & 6 & 72.99 & 0 & 0 & 36 & 24.4 \\
\hline $65+$ & 8 & $12 \cdot 2$ & 2 & 129.8 & 0 & 0 & 10 & 13.96 \\
\hline Total & 96 & $14 \cdot 6$ & 34 & $32 \cdot 41$ & 6 & $17 \cdot 01$ & 136 & $17 \cdot 05$ \\
\hline \multicolumn{2}{|c|}{$\begin{array}{l}\text { Age } \\
\text { adjusted }\end{array}$} & $14 \cdot 6$ & & $50 \cdot 63$ & & $19 \cdot 11$ & & 17.62 \\
\hline
\end{tabular}

64 of 45 per 100000 and Polynesian women in the same age group 99 per 100000 . Age-adjusted rates show that SLE is 3.5 times commoner in Polynesians than whites $(50.63$ versus 14.6 per 100000$)$, and this is statistically significant (chi-square $32 \cdot 2, \mathrm{p}<0 \cdot 001$ ). The difference in rate occurs in all age groups, but there is significant inhomogeneity (Mantel-Haenszel test, chi-square $20 \cdot 5, \mathrm{p}<0 \cdot 001$ ) between age groups due to sample size. The mean age at onset for whites was 32 years and Polynesians 25.3 years. This difference may be partly explained by the different age distribution in the 2 populations. The 'other races' category, which is mainly Chinese and Indian, shows an intermediate prevalence rate of 19.11 per 100000 (Table 4).

Age-specific mortality rates for SLE were calculated from the white population as standard. This procedure showed the rate for Polynesians to be 13.0 and whites 2.5 per million person years. Survival curves were constructed which showed the Polynesian 6-year survival to be $87 \%$ and whites $96 \%$. This difference was not significant (log rank test), suggesting that there is no difference in the severity of the disease in the 2 populations.

\section{Discussion}

A study from San Francisco of members of a prepaid health plan that cares for 125000 people showed the prevalence of definite SLE to be 51 per 100000 . The rate for women aged 15 to 64 years was 142 per 100000 and in black women in the same age group 408 per 100000 . It should be noted that in this study the investigators had access to complete medical records. Similar ethnic differences have been confirmed by other studies, but the prevalence rates have been considerably lower. This is particularly true of those based on hospital records, for this method undoubtedly leads to the exclusion of many milder cases. In a study from Hawaii, ${ }^{7}$ for example, the rates for whites was 5.8 per 100000 compared with 20 per 100000 for Chinese, Philipinos, and Polynesians.

Our study suggests that in Auckland SLE is also substantially more common among people of black (Polynesian) ancestry. The overall prevalence rates lie somewhere between the 2 studies mentioned above, which is in keeping with our method of finding patients. Inevitably some cases in the community will have been missed, particularly in a retrospective survey.

Racial differences in the severity of the disease are more difficult to assess. Taking death as the end point we have shown that the age-specific mortality rate is substantially greater in the Polynesian group. These rates are similar to those obtained for blacks in the United States. ${ }^{9}$ However, life table analysis failed to demonstrate a significant difference, suggesting that Polynesian survival is no different from that of whites. The overall survival rates were similar to those observed in San Francisco. ${ }^{2}$

An explanation for these differences in prevalence is lacking. In particular the evidence from HLA tissue typing studies has been unhelpful. While there is no clearly defined association of SLE and a particular tissue type, a weak association with HLA B8 has been found in two studies. ${ }^{14}{ }^{15}$ However, in North America, the frequency of HLA B8 has been found to be $17 \cdot 1 \%$ in whites and $5 \cdot 2 \%$ in blacks. ${ }^{16} \mathrm{~A}$ preliminary study from New Zealand has found much the same situation, with HLA B8 in $24 \%$ of whites and $2 \%$ of Polynesians (Woodfield D G, personal communication).

\section{References}

1 Siegel M, Lee S L. The epidemiology of systemic lupus erythematosus: results of a population study in New York City. Population studies of the Rheumatic Diseases. International Congress Series 148. New York, 1966.

2 Fessel J W. Systemic lupus erythematosus in the community. Arch Intern Med 1974; 134: 1027-34.

3 Siegel M, Holley H L, Lee S L. Epidemiologic studies on systemic lupus erythematosus. Arthritis Rheum 1970; 13: 802-11.

4 Frank A O. Apparent predisposition to systemic lupus erythematosus in Chinese patients in West Malaysia. Ann Rheum Dis 1980; 39: 266-9.

5 Hai B T, Teik K O. Systemic lupus erythematosus-an analytical study of eighty cases in Singapore. Singapore Med J 1971; 12: 92-9.

6 Wilson W A, Hughes G R V. Rheumatic disease in Jamaica. Ann Rheum Dis 1979; 38: 320-5.

7 Serdula M K, Rhoads G G. Frequency of systemic lupus erythematosus in different ethnic groups in Hawaii. Arthritis Rheum 1979; 22: 328-33.

8 Kaslow R A, Masi A T. Age, sex and race; effects on mortality from systemic lupus erythematosus in the United States. Arthritis Rheum 1978; 21: 473-9.

9 Gordon M F, Stolley P D, Schinnar R. Trends in recent systemic lupus erythematosus mortality rates. Arthritis Rheum 1981; 24: $762-9$. 
10 Fries J F, Holman H R. Systemic lupus erythematosus: a clinical analysis. Major problems in internal medicine, 6, New York: Sanders, 1975.

11 Diagnostic and Therapeutic Committee of the American Rheumatism Association section of the Arthritis Foundation. Preliminary criteria for the classification of systemic lupus erythematosus. Bull Rheum Dis 1971; 21: 643-8.

12 Mantel N, Haensel W. Statistical aspects of the analysis of data from retrospective studies of disease. J Natl Cancer Inst 1959; 22: $719-48$.

13 Merrell M, Shulman L E. Determination of prognosis in chronic disease illustrated by systemic lupus erythematosus. J Chronic Dis 1955; 1: 12-32.

14 Grumet F C, Couckell A, Bodner J G, et al. Histocompatibility antigens associated with systemic lupus erythematosus. $N$ Engl $J$ Med 1971; 285: 193-6.

15 Russell A S, Barraclough D R E. HLA studies in other rheumatic diseases. Clin Rheum Dis 1977; 3: 365-75.

16 Reeve C E. HLA B8. In: Duquesnoy R J, Fuller TC, eds. The first HLA workshop of the Americas conference held at UCLA on December 16-17, 1975. DHEW publication No. (NIH) 76-1064, 1976: 57. 